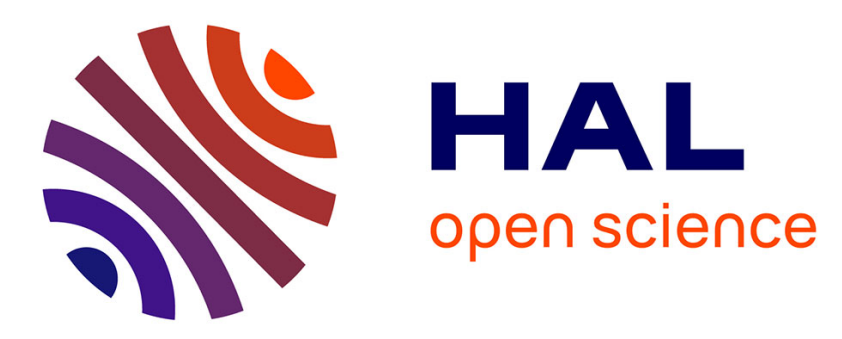

\title{
Fluorescent solar concentrators using liquid solutions
}

\author{
A. Filloux, J. Mugnier, J. Bourson, B. Valeur
}

\section{To cite this version:}

A. Filloux, J. Mugnier, J. Bourson, B. Valeur. Fluorescent solar concentrators using liquid solutions. Revue de Physique Appliquée, 1983, 18 (5), pp.273-279. 10.1051/rphysap:01983001805027300 jpa00245091

\section{HAL Id: jpa-00245091 https://hal.science/jpa-00245091}

Submitted on 1 Jan 1983

HAL is a multi-disciplinary open access archive for the deposit and dissemination of scientific research documents, whether they are published or not. The documents may come from teaching and research institutions in France or abroad, or from public or private research centers.
L'archive ouverte pluridisciplinaire HAL, est destinée au dépôt et à la diffusion de documents scientifiques de niveau recherche, publiés ou non, émanant des établissements d'enseignement et de recherche français ou étrangers, des laboratoires publics ou privés. 


\title{
Fluorescent solar concentrators using liquid solutions
}

\author{
A. Filloux, J. Mugnier, J. Bourson and B. Valeur $\left({ }^{*}\right)$ \\ Conservatoire National des Arts et Métiers, 292, rue Saint-Martin, 75003 Paris, France
}

(Reçu le 9 novembre 1982, accepté le 4 février 1983)

\begin{abstract}
Résumé. - Divers aspects des concentrateurs solaires fluorescents à base de solutions liquides de colorants organiques sont considérés. La forme géométrique du concentrateur a peu d'influence sur son efficacité. Les sources de perte de lumière sont examinées en détail. Une méthode est proposée pour séparer la contribution relative de la matrice et du colorant dans l'atténuation de la lumière. Une attention particulière est apportée aux pertes par réflexions multiples et par réabsorption des photons de fluorescence. La longueur d'atténuation s'avère plus grande lorsqu'une mince couche de solution concentrée est utilisée.
\end{abstract}

\begin{abstract}
Various aspects of fluorescent solar concentrators using liquid solutions of organic dyes are considered. No significant difference in efficiency is observed between various collector geometries. The origins of light losses are carefully examined. A method is proposed for separating the relative contribution of the dye and the matrix in the total attenuation of light. Special attention is paid to light losses by imperfect multiple reflections and by reabsorption of fluorescence photons. Attenuation lengths in collectors using a thin layer of concentrated solution are significantly longer.
\end{abstract}

1. Introduction. - Using the concept of light trapping and guiding in scintillators, Weber and Lambe [1], following the suggestion of Garwin [2], proposed in 1976 a new type of solar concentrator. The collector consists of a transparent plate doped with fluorescent molecules. Owing to its high refractive index, the plate behaves as a light pipe for the fluorescence photons which are thus guided towards the edge where solar cells are set. This collector permits not only high concentration factors, but also a better fit to the spectral response of the solar cells thanks to the frequency conversion in the fluorescence phenomenon. This type of concentrator does not require sun tracking and remains efficient with diffuse light.

In most of the systems proposed so far, the plate consists of an organic solid transparent matrix, usually polymethylmethacrylate (PMMA), doped with organic dyes [1-4]. Inorganic glasses doped with inorganic ions (uranyl or rare earth ions) have also been suggested $[1,6,7]$. Two recent reviews are devoted to this subject $[8,9]$.

Fluorescent solar concentrators (FSC) using liquid solutions contained between transparent plates have received little attention so far $[5,10]$. Nevertheless, this type of collector appears to be interesting for the following reasons :

(*) A qui toute correspondance doit être envoyée. a) The photostability of organic dyes is generally poor whereas a stability over several years is required in an actual operating system. Furthermore, there is no problem of stability with glasses doped with inorganic ions, but they will probably not be manufactured because of their very high price. Alternatively, the lack of stability of organic dyes can be overcome by using a device in which a liquid solution of dyes can be renewed as it deteriorates.

b) In non-viscous solutions of some organic dyes in polar solvents, the phenomenon of solvent relaxation can cause a large red-shift of the fluorescence spectrum to occur; the consequent decrease in the overlap between absorption and fluorescence spectra, reduces the loss of light by reabsorption of the fluorescence photons by the dye itself.

c) The use of liquid solutions makes the investigations easier as regards the characteristics and the performances of FSC. As the matter of fact, it is easy to change the geometry of the collector, the thickness of the absorbing layer, the dye concentration...

The purpose of the present work is not to measure prototype efficiencies but to examine the influence of various parameters with special attention to light attenuation. 
2. Preliminary investigations with a planar tank. 2.1 EXPERIMENTAL SET-UP. - The experiments were carried out with a square tank $(20 \times 20 \mathrm{~cm})$ made of polymethylmethacrylate (PMMA). In this preliminary investigation, the dye solution was in contact with air so that the geometry of the collector can be easily changed by moving small aluminum mirrors, vertically held by PMMA blocks, set out in the solution. A diagram of the experimental set-up is shown in figure 1. This device is not, of course, a prototype of a liquid FSC which would obviously consist of two transparent plates containing the solution. The advantage of the present system is its versatility in the study of collector geometry.

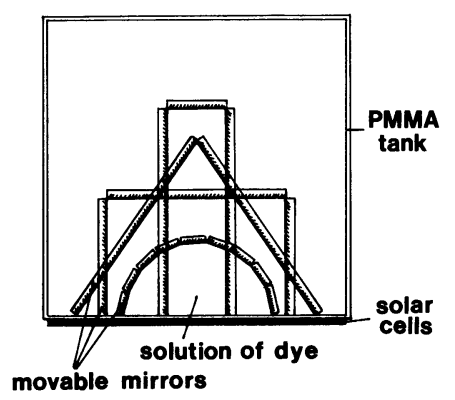

Fig. 1. - Tank schematic. The geometry is variable thanks to movable aluminum mirrors.

The solvent was chosen to be dimethylsulfoxide (DMSO) since its refractive index (1.478) is close to that of PMMA (1.493). In addition, this solvent is polar and thus favours solvent relaxation. The fluorescent dyes, rhodamine $6 \mathrm{G}$ or Coumarine 6 , were used at a concentration of $10^{-.4} \mathrm{M}\left(\mathrm{mol} .1^{-1}\right)$. This concentration corresponds to a maximum of efficiency (see section 3.1).

In this study, we used commercial Si-cells (Société Anonyme des Télécommunications, ref. 302, or France-
Photon, ref. CCO6). The solar cells were coupled to the tank with glycerol for optical matching.

The tank was illuminated by a projector equipped with a $575 \mathrm{~W}$ Osram HMI lamp (colour temperature : $5600 \mathrm{~K}$ ) and a Fresnel lens. The spectral characteristics of this projector are quite comparable to that of the AMO solar spectrum in the range 0.38-0.9 $\mu \mathrm{m}$. However, in our experimental set-up, the energy received in the collector is 20 times lower than the AMO energy which implies a correcting factor in our measurements.

\subsection{INFLUENCE OF THE COLLECTOR GEOMETRY. -} Various collector shapes can be obtained thanks to proper positions of small mirrors set out in the solution of rhodamine $6 \mathrm{G}$ in DMSO $\left(10^{-4} \mathrm{M}\right)$ (Fig. 1). The thickness of the solution is chosen to be $5 \mathrm{~mm}$. The effective illuminated area is kept constant and equal to $25 \mathrm{~cm}^{2}$. Therefore, the number of solar cells that are edge-mounted depends on the geometry; thus the concentration ratio is best defined as the following ratio :

$$
c=\frac{I_{\mathrm{SC}}}{I_{\mathrm{SC}}^{0}}
$$

where $I_{\mathrm{SC}}$ is the total short-circuit current of the cells coupled to the collector and $I_{\mathrm{SC}}^{0}$ is the value obtained with the same cells under direct insolation by the projector. The geometric gain is given by :

$$
G=\frac{S}{s}
$$

where $S$ is the illuminated area and $s$ the total surface covered with the cells.

The values of $G, I_{\mathrm{SC}}, I_{\mathrm{SC}}^{0}$ and $c$ for various collector geometries are reported in table I. Before examining the influence of geometry, it is worthwhile observing the effect of a mirror underneath collector which increases absorption of the incident light, as previously suggested $[5,11]$. However, experiments with an

Table I. - Concentration ratios $\left(c=I_{\mathrm{sc}} I_{\mathrm{SC}}^{0}\right)$ for various collectors. The short-circuit currents are multiplied by

\begin{tabular}{|c|c|c|c|c|c|c|c|c|c|c|}
\hline Shape & $\begin{array}{c}\text { Dimensions } \\
(\mathrm{cm})\end{array}$ & $\begin{array}{c}\mathbf{s} \\
\left(\mathrm{cm}^{2}\right)\end{array}$ & G & $\begin{array}{l}\mathrm{I}_{\mathrm{SC}}^{\circ} \\
\text { (mA) }\end{array}$ & \multicolumn{2}{|c|}{$\begin{array}{l}\text { without back } \\
\text { mirror or reflector }\end{array}$} & $\begin{array}{l}\text { with } \\
\mathrm{I}_{\mathrm{SC}} \\
(\mathrm{mA})\end{array}$ & $\begin{array}{l}\text { irror } \\
c\end{array}$ & $\begin{array}{c}\text { with d } \\
\text { I }_{\mathbf{S c}} \\
(\mathrm{mA})\end{array}$ & $\begin{array}{l}\text { reflector } \\
\text { c }\end{array}$ \\
\hline square $\square$ & $5 \times 5$ & 2.50 & 10 & 56 & 31 & 0.55 & 21.8 & 0.39 & 45.2 & 0.81 \\
\hline \multirow{4}{*}{ rectangle } & $\begin{array}{l}L=20 \\
1=1.25\end{array}$ & 0.63 & 40 & 16.8 & 14 & 0.83 & 11.5 & 0.68 & 20.4 & 1.21 \\
\hline & $\begin{array}{l}I=12.5 \\
1=2\end{array}$ & 1.0 & 25 & 22.4 & 16 & 0.71 & 13.7 & 0.61 & 23.4 & 1.04 \\
\hline & $\begin{array}{l}L=10 \\
1=2.5\end{array}$ & 1.25 & 20 & 28 & 16.6 & 0.59 & 16.8 & 0.60 & 24.2 & 0.86 \\
\hline & $\begin{array}{l}L=2.5 \\
1=10\end{array}$ & 5.0 & 5.0 & 112 & 43 & 0.38 & 40.3 & 0.36 & 62.8 & 0.56 \\
\hline \multirow{4}{*}{$\sum_{b}^{\text {triangle }}$} & $\begin{array}{l}h=20 \\
b=2.5\end{array}$ & 1.25 & 20 & 28 & 16.6 & 0.59 & 16.8 & 0.60 & 24.2 & 0.86 \\
\hline & $\begin{array}{l}\mathrm{h}=12.5 \\
\mathrm{~b}=4\end{array}$ & 2.0 & 12.5 & 44.8 & 24 & 0.54 & 20.6 & 0.46 & 35.0 & 0.78 \\
\hline & $\begin{array}{l}h=10 \\
b=5\end{array}$ & 2.5 & 10 & 56 & 32 & 0.57 & 22.4 & 0.40 & 46.6 & 0.83 \\
\hline & $\begin{array}{l}h=5 \\
b=10\end{array}$ & 5.0 & 5.0 & 112 & 43.6 & 0.39 & 42.6 & 0.38 & 63.6 & 0.57 \\
\hline$\overbrace{}^{\text {half disk }}$ & $R=4$ & 4.0 & 6.3 & 89.6 & 37.4 & 0.42 & 37.6 & 0.42 & 55.0 & 0.61 \\
\hline
\end{tabular}
a correcting factor so that they represent an AMO response (see text). (Solution of rhodamine 6G in DMSO). 
aluminum mirror placed inside the solution at the bottom of the tank show that in many cases some loss in efficiency is observed instead of a gain (see Table I). As a matter of fact, a metallic reflection always introduces some loss contrary to total reflection. Consequently, it is desirable to preserve total relfections by using an air-gap coupled reflector. In addition, a diffuse reflector is known to be superior to a metallic reflector [12]. Table I shows that such a diffuse reflector made of alumina improves the concentration factor : a gain of about $45 \%$ is obtained whatever the collector geometry.

As regards the collector geometry, the best comparison should be done with the same illuminated area and the same surface of cells (i.e. at constant geometric gain). This is possible in some cases reported in table II. The parameter which is to be compared is the optical efficiency $\eta_{\text {opt }}$ defined as the output energy at the edge of the collector divided by the energy received by the collector. According to the relation

$$
c=\eta_{\text {opt }} G
$$

the optical efficiency has been calculated as the ratio of the concentration ratio and the geometric gain given in table I. Table II clearly shows that there is no significant difference in efficiency for the various shapes. Moreover, the variations in $I_{\mathrm{SC}}$ as a function of $s$ (surface of the cells) are almost linear (Fig. 2) which confirm the absence of significant dependence on the collector geometry.

Table II. - Comparison of optical efficiencies for various shapes of collector. (Solution of rhodamine 6G in DMSO.)

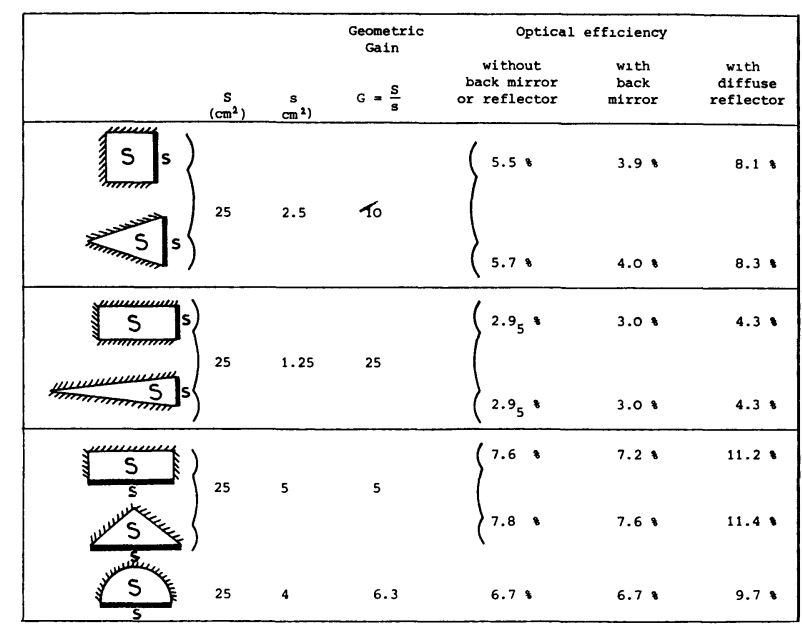

Goetzberger and Greubel [5] proposed a triangular shape on the basis of qualitative considerations, the number of metallic reflections at the edges being minimum. Our study does not confirm that the triangular shape is the most efficient. Nevertheless, as noted by these authors, large areas can be continuously covered with triangular collectors.

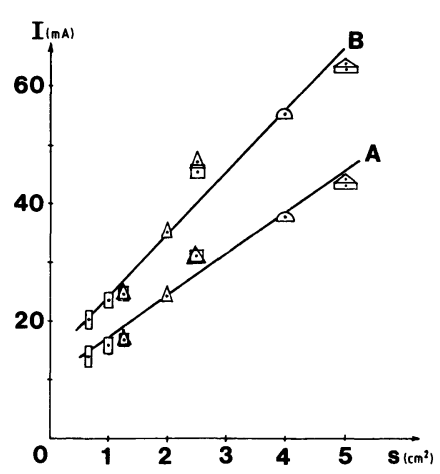

Fig. 2. - Variations in short-circuit current as a function of the total surface of edge mounted solar cells for various shapes : triangles $(\triangle)$, square $(\square)$, rectangles $(\square)$, halfdisk (ص). A : tank filled with a solution of rhodamine 6G in DMSO $\left(10^{-4} \mathrm{M}\right)$. B : same tank with an air-gap coupled diffuse reflector.

Identical experiments were carried out with a solution of coumarine 6 . No significant difference with rhodamine $6 \mathrm{G}$ was found.

After this preliminary investigation, attention should be paid to the phenomena responsible for light attenuation.

\section{Experimental investigation of light attenuation. -}

3.1 Light ATteNUATION CURVES AS A FUNCTION OF DYE CONCENTRATION. - Since the geometry of the collector has a minor effect on its efficiency, it is valid to measure the fluorescence light attenuation with a long rectangular PMMA tank (length : $200 \mathrm{~mm}$, width : $20 \mathrm{~mm}$, depth : variable). A solar cell is coupled to the end surface of the tank with glycerol for optical matching. The surface opposite to the output end absorbs light thanks to hot coating of paraffin doped with charcoal. The fluorescent solution is illuminated with monochromatic light over a small area at various distances from the output end by means of a modified AMINCO SPF 500 spectrofluorometer. Accurate displacements of the tank are achieved by an optical bench.

The attenuation curves recorded with rhodamine 6G solutions in DMSO are presented in figure 3. The thickness of the dye solution is $3 \mathrm{~mm}$ and the total thickness of the tank is $10 \mathrm{~mm}$. The excitation wavelength corresponds to the maximum of the absorption spectrum (i.e. $548 \mathrm{~nm}$ ). The attenuation curves are of similar shape whatever the concentration. At small distances (a few centimeters), there is a sharp decrease in intensity which can be explained by the reabsorption of fluorescence photons by the dye itself (i.e. the absorption of the short-wavelength tail of the fluorescence spectrum which overlap the absorption spectrum). Then the intensity decreases exponentially with increasing length.

Owing to the reabsorption effect the attenuation length, which corresponds to a decrease of $1 / e$ in the relative intensity, decreases with increasing concen- 


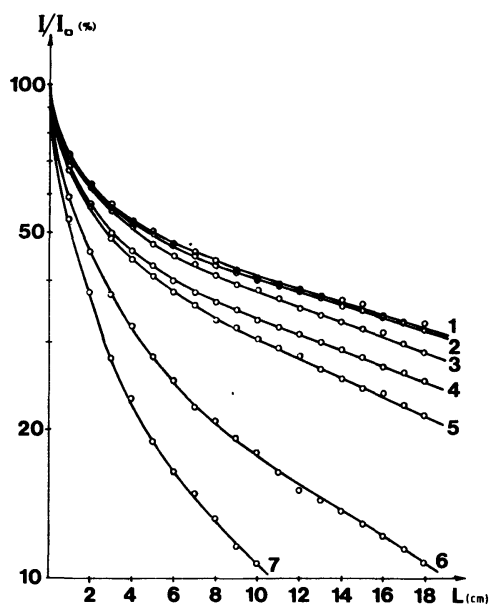

Fig. 3. - Light attenuation in a rectangular tank (dimensions : $200 \times 20 \mathrm{~mm}$, external thickness : $10 \mathrm{~mm}$, solution thickness : $3 \mathrm{~mm}$ ) filled with solutions of rhodamine $6 \mathrm{G}$ at various concentrations : $10^{-5} \mathrm{M}(1), 5 \times 10^{-5} \mathrm{M}(2)$, $10^{-4} \mathrm{M}(3), 5 \times 10^{-4} \mathrm{M}(4), 10^{-3} \mathrm{M}(5), 5 \times 10^{-3} \mathrm{M}(6)$, $10^{-2} \mathrm{M}(7)$.

tration (Fig. 4). However, the total short-circuit current of the solar cells goes through a maximum at a concentration of $10^{-4} \mathrm{M}$. Such a maximum can be interpreted as a result of the competition between the gain in efficiency of absorption and the loss due to reabsorption, as the concentration increases.

Thus, the reabsorption of fluorescence photons appears to be the a serious problem in this type of light collector, but the loss of light due to the matrix is not negligible and should be carefully examined.

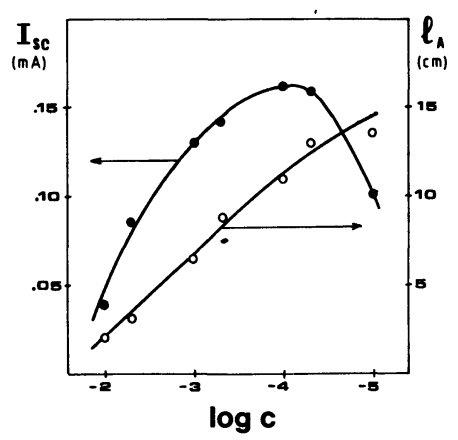

Fig. 4. - Attenuation length $\left(l_{\mathrm{A}}\right)$ and total short-circuit current $\left(I_{\mathrm{SC}}\right)$ versus dye concentration (in mol.1-1). The conditions are the same as in figure 3.

3.2 Light attenUation DUE to the Matrix. The attenuation of light which is carried along a transparent body by total internal reflection is due to absorption and scattering by the matrix itself (PMMA and solvent) and to surface imperfections.

PMMA has a good transparency for visible radiations and, despite its microheterogeneity (scattering centres and microscopic bubbles), its absorption coefficient is quite low. The attenuation of light is mainly due to surface imperfections (microscopic cracks, scratches, rough patches). These imperfections disturb the total internal reflection and some part of the trapped light is scattered out and lost.

The absorption coefficients of PMMA and the solvent (DMSO) were first determined by using a $\mathrm{He}-\mathrm{Ne}$ laser and measuring the light attenuation (without internal reflections) through a long rectangular PMMA rod or a long tank filled with DMSO. The values are $\alpha_{\mathrm{PMMA}}=1.3 \times 10^{-3} \mathrm{~cm}^{-1}$ and $\alpha_{\text {DMSO }}=5.2 \times 10^{-3} \mathrm{~cm}^{-1}$.

The testing set-up shown in figure 5 allowed us to determine the reflection coefficient of a total reflection in a tank filled with DMSO. The attenuation of the incident laser light $I_{0}$ due to absorption along an optical path $D$ and to $N$ internal reflections is expressed by :

$$
I=I_{0} \rho^{N} \exp (-\alpha D)
$$

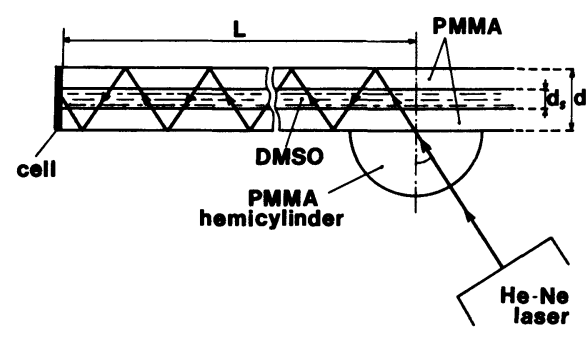

Fig. 5. - Testing set-up for the measurement of the internal reflection coefficient $\left(d=9 \mathrm{~mm}, d_{\mathrm{s}}=3 \mathrm{~mm}\right)$. Several distances $L$ and incident angles $i$ are used.

Therefore, $\rho$ can be calculated from the following relation

$$
\ln \rho=\frac{1}{N}\left[\ln \frac{I}{I_{0}}+D \alpha\right] .
$$

If $d$ is the total thickness of the tank and $d_{\mathrm{s}}$ the thickness of solvent, the mean absorption coefficient is given by :

$$
\alpha=\frac{d-d_{\mathrm{s}}}{d} \alpha_{\mathrm{PMMA}}+\frac{d_{\mathrm{s}}}{d} \alpha_{\mathrm{DMSO}} .
$$

The optical path $D$ for an incident angle $i$ (see Fig. 5) and for $N$ reflections is :

$$
D=\frac{d}{\cos i}\left(N+\frac{1}{2}\right)
$$

In order to increase the accuracy in the determination of $\rho$ by means of equation (2) in conjunction with equation (4), several values of $i$ and $N$ have been chosen. The average value of $\rho$ is then found to be $0.935 \pm 0.007$.

It should be noted that this value takes into account not only the loss by internal reflection at the interface 
PMMA/air, but also at the interfaces PMMA/DMSO since the optical matching between these two media is not perfect.

\subsection{Separation OF THE Light attenUation DUE} TO THE MATRIX AND THE DYE. - It is of interest to examine the role played by the dye alone in the light attenuation $I / I_{0}$ as a function of the distance $L$ from the output end (curves of Fig. 3). The only attempt to separate matrix and dyes losses has been reported by Wittwer et al. [13] but these authors do not give any information about the method that they used. The total attenuation factor is the product of the attenuation factor of the dye and that of the matrix :

$$
\frac{I}{I_{0}}=F_{\text {tot }}=F_{\text {dye }} \times F_{\text {mat }} .
$$

$F_{\text {mat }}$ depends of the optical path $D$ and the number $N$ of internal reflections, according to equation (1) :

$$
F_{\text {mat }}=\rho^{N} \exp (-\alpha D) .
$$

This expression can be rewritten as a function of the distance $L$ and the output angle $\theta$ at the edge of the tank. This angle $\theta$ is defined with respect to the tank axis in the plane perpendicular to both the tank surface and the output edge.

Since

$$
D=\frac{L}{\cos \theta}
$$

and

$$
N=\frac{L}{d} \tan \theta
$$

we obtain :

$F_{\text {mat }}(L, \theta)=\exp \left(\frac{L}{d} \cdot \tan \theta \cdot \ln \rho-\alpha L \frac{1}{\cos \theta}\right)$.

The mean matrix attenuation factor at a distance $L$ is obtained by averaging $F_{\text {mat }}$ over the angular distribution of the fluorescence intensity at the output end of the tank. This three-dimensional distribution can be approximated by the two-dimensional distribution $\varphi(\theta)$ in the plane perpendicular to both the tank surface and the output edge.

Thus,

$$
\bar{F}_{\text {mat }}(L)=\frac{\int_{-\theta_{\mathcal{c}}}^{\theta_{\mathrm{c}}} F_{\text {mat }}(L, \theta) \cdot \varphi(\theta) \mathrm{d} \theta}{\int_{-\theta_{\mathrm{c}}}^{\theta_{\mathcal{c}}} \varphi(\theta) \mathrm{d} \theta},
$$

where $\theta_{\mathrm{c}}=\frac{\pi}{2}-i_{\mathrm{c}}\left(i_{\mathrm{c}}\right.$ is the critical value of the angle $i$ for internal reflection between a ray inside and the surface normal $: \sin i_{\mathrm{c}}=1 / n$. With $n=1.493, \theta_{\mathrm{c}}=48^{\circ}$ ).
The angular distribution can be determined by using the testing set-up shown in figure 6. The tank filled with a solution of rhodamine $6 \mathrm{G}$ in DMSO is illuminated with monochromatic light over a small area at a distance $L$ from the output end where a PMMA hemicylinder is set. The measurement of light intensity at various angles $\theta$ is performed by an optical fibre (coupled to the hemicylinder with glycerol) in conjunction with the detection system of the AMINCO SPF 500 spectrofluorometer.

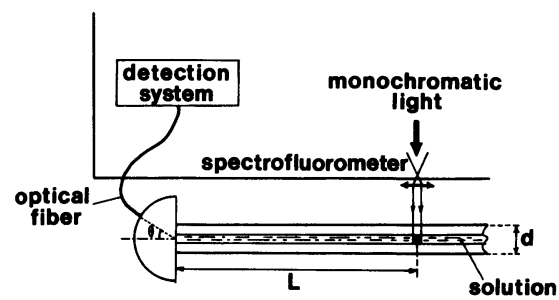

Fig. 6. - Testing set-up for the measurement of the angular distribution of the fluorescence intensity at the output end of the tank.

The angular distributions for $L=15 \mathrm{~cm}$ and $19 \mathrm{~cm}$ are shown in figure 7 . Since these distributions $\varphi(\theta)$ decrease rapidly at the edge of the distribution, it seems reasonable, in a first approach, to approximate the distribution by a rectangular distribution from $-45^{\circ}$ to $+45^{\circ}$. With such a distribution, $\bar{F}_{\text {mat }}(L)$ is evaluated by means of equation (7) together with equation (6) and the values of $\alpha$ and $\rho$ determined in section 3.2. Then $F_{\text {dye }}$ is calculated as follows :

$$
F_{\text {dye }}(L)=\frac{F_{\text {tot }}(L)}{\bar{F}_{\text {mat }}(L)} .
$$

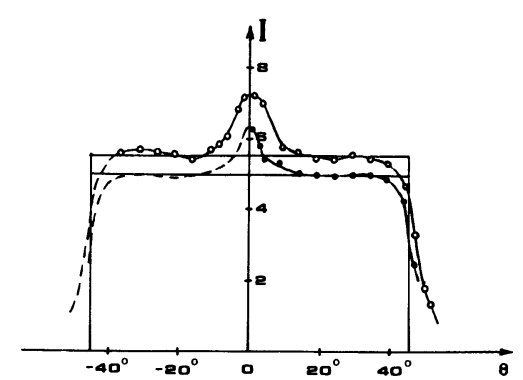

Fig. 7. - Angular distribution of the fluorescence intensity (arbitrary units) for $L=15 \mathrm{~cm} \mathrm{(O)} \mathrm{and} L=19 \mathrm{~cm}(\odot)$.

Figure 8 shows the results obtained with a solution of rhodamine $6 \mathrm{G}$ in DMSO $\left(10^{-4} \mathrm{M}\right)$. The attenuation curve relative to the dye alone clearly reveals not only the strong reabsorption effect at small distances, but also a significant attenuation at longer distances which is due to possible residual absorption of the dye across the whole emission band. This residual 


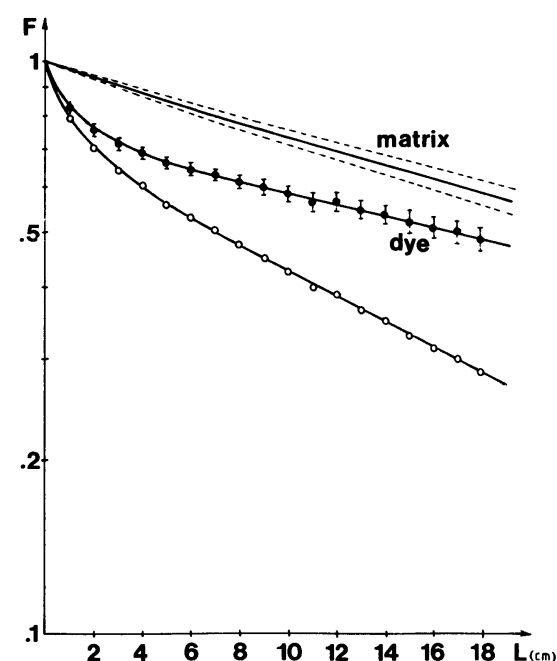

Fig. 8. - Separation of light attenuations by the matrix and the dye $(0)$ from the total attenuation $(0)$ for a solution of rhodamine $6 \mathrm{G}$ in DMSO $\left(10^{-4} \mathrm{M}\right)$. Dimensions of the tank : $200 \times 20 \times 10 \mathrm{~mm}$, thickness of the solution : $3 \mathrm{~mm}$. The broken lines define the confidence range taking into account the standard deviation in the value of the internal reflection coefficient.

absorption requires further attention and will be examined in a subsequent paper devoted to the reabsorption problem.

3.4 INFLUENCE OF DYE SOLUTION THICKNESS. Various rectangular tanks have been made : the external dimensions are kept constant $(200 \mathrm{~mm} \times$ $20 \mathrm{~mm} \times 10 \mathrm{~mm}$ ), but the thickness of the internal compartment is variable. The results obtained with rhodamine $6 \mathrm{G}$ solutions in DMSO are reported in table III.

Table III. - Influence of the solution thickness on the attenuation length. (Solution of rhodamine 6G in DMSO.)

\begin{tabular}{|c|c|c|c|}
\hline concentration & $\begin{array}{c}\text { Solution } \\
\text { Thickness } \\
(\mathrm{mm})\end{array}$ & $\begin{array}{c}\text { Attenuation } \\
\text { Length } \\
(\mathrm{cm})\end{array}$ & $\begin{array}{c}\text { Relative } \\
\text { Intensity } \\
(8)\end{array}$ \\
\hline $10^{-4} \mathrm{M}$ & 1.5 & 13.5 & 100 \\
$10^{-4} \mathrm{M}$ & 3.0 & 11 & 97 \\
$10^{-4} \mathrm{M}$ & 6.0 & 7.0 & 94 \\
\hline $5.10^{-5} \mathrm{M}$ & 6.0 & 9.0 & 96 \\
\hline $10^{-3} \mathrm{M}$ & 0.1 & 18 & 88 \\
\hline
\end{tabular}

At constant concentration, the attenuation length decreases with increasing thickness. This result is to be expected since the optical path in the fluorescent solution is longer at larger thickness and therefore, the reabsorption effect is stronger.

More interesting is the effect observed when changing the concentration in order to keep constant the optical density, as the thickness is changed (for instance by using two tanks such that the thicknesses $d_{\mathrm{s}}$ are 3 and $6 \mathrm{~mm}$ and the concentrations $10^{-4}$ and $5 \times 10^{-5} \mathrm{M}$ respectively, the total thickness $d$ of the tank being kept constant). It turns out that the attenuation length is significantly longer for the smaller thickness (Table III).

In principle, there should not be any difference between homogeneously and inhomogeneously doped sheets when the overall absorbance is the same. However, the fluorescence photons are emitted isotropically and therefore the probability of reabsorption of these photons depends on the spatial distribution of the surrounding dye molecules. As a limiting case, one could imagine a monomolecular sheet of dye molecules : the probability of reabsorption would then be negligible.

Our findings are consistent with the proposals of using thin fluorescent films deposited on an undoped glass or plastic substrate $[14,15]$. However, when the thickness of the absorbing layer is reduced, the dye concentration has to be increased proportionally in order to retain full absorption, but there is a limit of dye solubility-in common solvents. An air-coupled diffuse reflector can help in increasing absorption (see section 2.2).

Let us remark that, in order for the trapping to be efficient in the undoped containing material (as opposed to having a significant trapping in the solution alone), the refractive index of the solvent should be very close to that of the undoped material. This is indeed the case of DMSO $(n=1.478)$ used in conjunction with PMMA $(n=1.493)$.

4. Concluding remarks. - Liquid collectors are claimed to be less efficient for light concentration since they are rather thick because of the containing sheets. However, the present study shows that thin layers of concentrated solutions are advantageous as regards light attenuation. Therefore, an overall thickness of about $4 \mathrm{~mm}$ should be obtained. In addition, the concentration factor could be improved by using a taper at the output edge of the collector [16].

It is known that most dyes are less stable in a liquid solution than in a solid matrix, but careful removal of oxygen from the solution and drastic purification of dyes considerably improve the photostability in solution. At any rate, let us recall that the distinct advantage of a liquid collector is the possibility of replacing the dye solution.

In the present paper, we propose a method for separating the relative contribution of the dye and the matrix from the total attenuation of light, which makes the analysis of the phenomena easier. The attenuation due to the matrix is far from being negligible mainly because of the imperfect internal multiple reflections even with polished, clean PMMA. Outdoor tests have revealed that such losses dramatically 
increase with alteration of the surfaces (dust, scratches, ...) PMMA has been used in this study for convenience, but evidently the containing sheets would be glass plates in an actual configuration.

The study of light attenuation due to the dye (which can be separated from matrix effects by our method) emphasizes that reabsorption is the most serious problem in fluorescent dye concentrators. Two recent papers are devoted to this problem [17, 18]. Minimization of losses by reabsorption requires a small overlap between absorption and emission spectra i.e. a Stokes shift as large as possible. The Stokes shift depends first on the structure of the dye, but it depends also on its environment. Large Stokes shifts can be obtained with molecules whose dipolar moment is higher in the excited state than in the ground state, provided that the environment is fluid and polar [19]. This effect, called solvent relaxation, can be easily achieved in liquid collectors. In the case of solid collectors, Sah et al. [20] have suggested to add some DMSO to the monomer prior to polymerization so that local fluidy is preserved.

The synthesis of new dyes exhibiting large solvent relaxation effects is in progress in our laboratory. Their characteristics together with the implications regarding the reabsorption problem will be presented in a subsequent paper.

Acknowledgments. - This research was supported by a grant from the Centre National de la Recherche Scientifique.

\section{References}

[1] Weber, W. H., Lambe, J., Appl. Opt. 15 (1976) 2299.

[2] Garwin, R. L., Rev. Sci. Instrum 51 (1960) 1010.

[3] Swartz, B. A., Cole, T., Zewail, A. H., Opt. Lett. 1 (1977) 73.

[4] Lewitt, J. A., Weber, W. H., Appl. Opt. 16 (1977) 2684.

[5] Goetzberger, A., Greubel, W., Appl. Phys. 14 (1977) 123.

[6] Reisfeld, R., Neuman, S., Nature 274 (1978) 144

[7] ReISFELD, R., KaLISKY, Y., Nature 283 (1980) 281 ; Chem. Phys. Lett. 80 (1981) 178.

[8] Goetzberger, A., Wittwer, V., Solar Cells 4 (1981) 3.

[9] Reisfeld, R., Struct. Bonding 49 (1982) 2.

[10] Wood, J. R., Long, J. F., Conf. Record of the 13th IEEE Photovolt. Conf. 1978, p. 1158.

[11] Batchelder, J. S., Zewail, A. H., Cole, T., Appl. Opt. 18 (1979) 3090.
[12] KeIL, G., Nucl. Instrum Methods 87 (1970) 111.

[13] Wittwer, V., Heidler, K., Zastrow, A., GoetzBerger, A., 14th IEEE Photovoltaic Spec. Conf. 1980.

[14] Rapp, C. F., Boling, N. L., Conf. Record of the 13th IEEE Photovolt. Conf. 1978, p. 690.

[15] Viehmann, W., Frost, R. L., Nucl. Instrum Methods 167 (1979) 405.

[16] Goetzberger, A., Schirmer, O., Appl. Phys. 19 (1979) 53.

[17] Olson, R. W., Loring, R. F., FAyer, M. D., Appl. Opt. 20 (1981) 2934.

[18] Batchelder, J. S., Zewail, A. H., Cole, T., Appl. Opt. 20 (1981) 3733.

[19] LIPPERT, E., Z. Elektrochem. 61 (1957) 962.

[20] Sah, R. E., Baur, G., Kelker, H., 'Appl. Phys. 23 (1980) 369 . 